\title{
On The Multi-Stage Optimization in Supply Chain (A Case Study of WEMY Industries Limited)
}

\author{
Oyekan, E.A., Ewebajo, O.A. \& Temisan Gabriel O. \\ Department of Mathematical Sciences \\ Ondo State University of Science and Technology \\ Okitipupa, Ondo State, Nigeria. \\ E-mails: ea.oyekan@osustech.edu.ng, oluwaseunanuoluwapo14@gmail.com, temisangabriel@gmail.com \\ Phone: +2348034772630, +2348167260483, +2348164350198.
}

\begin{abstract}
This work proposes a new mathematical model based on a multi-objective solution for the optimization problem in supply chain. The analyzed supply chain includes the suppliers, manufacturers, distribution centers and wholesalers, considering that orders come from customers to wholesalers. A mathematical model that solves the optimization problem regarding durations and costs in the execution of customer orders is proposed. Many constraints are supported in this mathematical model such as suppliers and manufacturers capacities and balanced stocks. The aim of the proposed method is to find a near-optimal solution that minimizes criteria of cost and time along the whole supply chain process. The mathematical model was tested on WEMY Industries Limited supply chain, the results obtained by executing the heuristics approach and the mathematical model shows that it is more efficient than the heuristic. The GAP $15.02 \%$ gotten from the proposed model improves the actual solution, this will assist in reducing costs of production and transportation of the goods and profit will be maximized as the customer

of physical distribution and logistics emerged in the 1960s and 1970s. In the 1990s, a new name emerges: "Supply demands are meant genuinely respecting the delivery date of the customer.
\end{abstract}

Keyword: Supply Chain Management, Optimization, Linear program, Coordination \& Logistics.

Aims Research Journal Reference Format:

Oyekan, E.A., Ewebajo, O.A. \& Temisan Gabriel O. (2019 On The Multi-Stage Optimization in Supply Chain (A Case Study of

WEMY Industries Limited). Advances in Multidisciplinary Research Journal. Vol. 5. No. 1, Pp 61-74.

Article DOI: dx.doi.org/10.22624/AIMS/V5N1P7

Available online at www.aimsjournal.net

\section{INTRODUCTION}

Before the 1950s, logistics was thought of in military terms. It had to do with procurement, maintenance, and transportation of military facilities, material, and personnel. The study and practice Chain Management". This name took the logistics area by storm since so many in various business fields seemed to embrace it and saw activities of their areas imbedded in it. The supply chain industry's beginning of operations research as well as industrial engineering started with logistics. The founder of industrial engineering, Fredrick Winslow Taylor who wrote The Principles of Scientific Management in 1911, targeted the process improvement of manual loading in his work. Operations Research of analytics' value started during World War II for logistical military operational solutions in the 1940s. According to (Simchi-Levi et al., 1999), Supply Chain Management (SCM) is a set of approaches utilized to efficiently integrate suppliers, manufacturers, warehouses, and stores; so that merchandise is produced and distributed at the right quantities, to the right locations, and at the right time, in order to minimize system wide costs while satisfying service level requirements. SCM as defined by researchers and practitioners "encompasses the planning and management of all activities involved in sourcing and procurement, conversion, and all logistics management activities. 
More importantly, it also includes coordination and collaboration with channel partners, which can be suppliers, intermediaries, third-party service providers, and customers. Whereas, some SCM practitioners defines logistics to be that part of SCM that plans, implements, and controls the efficient forward and reverse flow and storage of goods, services, and related information between the point of origin and point of consumption in order to meet customer requirements. Therefore, SCM is viewed as managing product flows across multiple enterprises whereas logistics is seen as managing the product flow activities just within the firm.

Today, SCM is the oversight of all processes that occur from suppliers to manufacturer to wholesaler to retailer to consumer. It is a complex process that involves a great deal of global networks. SMC and optimization requires conflicting decisions, coordination and integration. Response time and product variability may affect Supply Chain (SC) design decisions. Problems associated with SC may be approached by mathematical modeling and optimization. The challenge through the SC is being responsive to customers with cost efficiency. Manufacturing processes also affect the efficiency of the SC. The current competitive business environment has made SCM more prominent than ever before. This is because the competitiveness of a company is to a large extent dependent on its SC. The SC, in a very broad sense comprises of all activities ranging from purchasing of raw materials, to the manufacturing and distribution of the finished products and reverse logistics.

\section{LITERATURE REVIEW}

\subsection{Optimization in Supply Chain}

In recent years, mathematical research in SC has developed many approaches and solutions, particularly for the minimization of duration and costs in the global SC on one hand, and for coordination between stages in SC on the other hand. The following sub-sections present some works established in the field of optimization to ensure good SC performances as reviewed by (El Yasmine et al. 2012).

\subsubsection{Inventory Management}

Replenishment and inventory management represents one of the issues in supply chain research. (Lim et al., 2006) considered various replenishment forms of raw materials, components and end-products in each node. In the same line of research, specific works have been proposed. For example, (Funaki, 2010) proposed an approach to solve the dynamic placement of inventory to meet challenges concerning compliance date of receipt in the machine industry. (Axsäter, 2015) proposed the inventory model parameterization as being an interesting field of research. Wherein different types of inventory model was introduced and with further discussion of single-echelon techniques used in practice to handle different stocks in a SC within inventory management. A study (by Zhalechian et al. 2016) showed where an inventory decision is incorporated in the Location Routing Problem (LRP) model. In this study, the authors aimed at sustainable design of a closed-loop Supply Chain Network (SCN) by considering economic, environmental and social measures within a Multi-Objective LRP model. (Bilgen, 2010) proposed an SCN. The proposed models are illustrated through a case study in consumer goods industry.

\subsubsection{Periods' Consideration in Supply Chain}

In the 90s, (McDonald and Karimi, 1997) proposed a multi-period linear programming model which takes into account the available processing time of all lines, transportation and shortage costs. Compared to our problem, this is an interesting case since demands with penalization and product families are considered. (Jin-Kwang et al., 2000) and (Kallrath, 2002) presented multi period optimization models that concern operational decisions and strategic planning for multi-site production networks respectively. (Chen et al., 2003) proposed an approach based on multi-product, multi-period model for multi objective planning solved by applying a two phase's fuzzy method. (Karimi et al., 2005) proposed a two-step procedure for the tank container management problem by combining an event based approach with a linear programming algorithm. (Huang and Karimi, 2006), (Al-Ameri et al., 2008) and (Dondo et al., 2008) used MILP (Mixed Integer Linear Programming) for transshipment operations of liquid chemical cargos, ship scheduling problem and operational level of multiple vehicle pickup and delivery problem respectively. 
Lazaros and Papageorgiou (2009) focused on mathematical programming models for supply chain optimization problems in the process industry at strategic and tactical levels.

\subsubsection{Uncertainty in Supply Chain}

To take into account uncertainty, (Voudouris, 1996) developed a mathematical model where the objective function aims at representing the flexibility of the plant to absorb unexpected demands. (Lee and kim, 2000) considered the stochastic character of the production and distribution capacities. (Aliev et al., 2007) included a fuzzy-genetic approach to aggregate production and transport based on fuzzy mathematical programming including uncertainty demand and production capacities. (Mula et al., 2010) and (Ryu et al., 2004) proposed a solution which incorporates production and holding capacities into demand uncertainty models by reformulating them with multi-parametric linear programming. (Selim et al., 2008) proposed a Multi objective mathematic model for decentralized and centralized collaborative production and transport planning in supply chains. Fuzzy programming has been used to incorporate uncertainty.

Jindal and Sangwan (2014) proposed a fuzzy Mixed Integer Linear Programming model in order to capture the uncertainty in demand, cost and other parameters. Petridis (2013) considered the demand uncertainty measuring the customers service level through the calculation of load time and normally distributed demand. In (Roghanian et al., 2007), the authors proposed a probabilistic bi-level linear multi objective programming model for supply chains using randomness in demand with production capacities and available resources. Also, (Peidro et al., 2008) proposed a review for supply chain quantitative models under uncertainty.

\subsubsection{Design of Supply Chain}

Overtime, researchers have considered vast possibilities of applying Operations Research (OR) techniques in the design of real-world systems. Some of the decisions which can bring about a noticeable improvement in the systems performance includes but not limited to proper selection of the facility's location, transportation modes and routes and inventory management policies. (Pourya and Oh Kyoung, 2016) presented a systematic review of some published contributions by focusing on two categories of OR approaches most recently applied for the design of SC systems: integrated mathematical modeling and Simulation Optimization (S-O) frameworks. A taxonomy analysis of the mentioned approach is presented based on the SC elements.

Also, a bibliometric analysis is conducted to provide possible gaps in the field. The study suggested that any conventional mathematical problem can be upgraded to a S-O framework to address real world problems while applying fewer assumptions. (Peirleitner et al. 2016) investigated a multi-stage and multiproduct Sc. Two different solution methods are compared, for determining optimal parameter setting for lot size $Q$ and re-order point $s$. The first method is an analytical optimization model. While the second method is a simulation-based optimization approach. The two real world transportation effects studied, which are truck load limit and mixed load, provide further insights into the optimization of real world multi-stage and multi-product supply chains. 


\section{PROPOSITION}

In this paper, we propose an approach that can provide near optimal solutions duration and cost along a known generic SC. This model will be applied to the case study, WEMY Industries Limited. A Nigerian owned private company and one of the fore-most manufacturers of lady sanitary pads (panty liner, ultra pads, underlay/under pad, net pad), baby and adult diapers, baby and adult wipes (facial wipes, sanitary wipes, hand sanitizer). The company partners with other manufacturing companies in China. Mathematical programming has been adopted to obtain a formal representation that could lead to the proof of optimality. However, the solution obtained is off-line, neither uncertainly nor perturbations are considered.

\subsection{Mathematical Formulation of the Problem}

In order to simplify the problem, (EI Yasmine et al. 2012) neglected the wholesalers. But for the purpose of this study, we included the wholsalers. The studied manufacturing company SC network can be represented by a multi-echelon graph $G(N, A)$, where the set of nodes $N$ are corresponding to the supply chain factors (suppliers, manufacturers, distributors, wholesalers and customer) and the set of arcs $A$ are the different flows (material or information). The global functioning of the manufacturing company SC is as follows: when the customers make an order to wholesaler of some products, this on a period $t(t=1 \ldots T)$ corresponding to its due-date. If no wholesaler is able to respond to the order (not enough in stock), orders are sent to the distribution center (DC).

The chosen DC responds to the order within the limited due-date and by optimizing different costs (inventory, handling inventory and transportation). In a case where no DC is available to respond to the order, such orders are then sent from the DC to manufacturers. The latter tries in turn to respond by looking to the stock or by producing it. The delivery and production lead time are taken into account to meet the customer's order. The manufacturers, depending on their needs, order the raw materials from suppliers that optimize costs (procurement and handling cost) with respect to the due dates of delivery. This global problem is modeled by a sub-division into four sub-problems according to the different echelons (customerwholesalers, wholesalers-DC, manufacturer and supplier). For each level, the objective function and the considered constraints are detailed in the following part. For comprehensive reason, the lower level (customer-DC) is described first. For the remaining features of our model, the following parameters and variables are considered.

\section{Indexes and Sets:}

A: planning horizon of $T$ periods. $t=1 \ldots T$

$\mathrm{S}$ : set of suppliers, $\mathrm{s}=1 \ldots \mathrm{S}$,

M: set of manufacturers, $m=1 \ldots M$,

$D$ : set of DCies, $d=1 \ldots D$,

$\mathrm{W}$ : set of wholesalers, $\mathrm{w}=1 \ldots \mathrm{W}$,

$C$ : set of customers, $c=1 \ldots C$,

$P$ : set of products, $p=1 \ldots P$,

$R$ : set of raw materials, $r=1 \ldots R$, 
Table 1: Parameters

\begin{tabular}{|l|l|}
\hline$D C_{c, p, t}$ & Demands of product $\mathrm{p}$ from customer $\mathrm{c}$ in period $\mathrm{t}$ \\
\hline$h d_{d, p}$ & Handling cost of product $\mathrm{p}$ at $\mathrm{DC} \mathrm{d}$ \\
\hline$h m_{m, r}$ & Handling cost of raw material $\mathrm{r}$ at manufacturer $\mathrm{m}$ \\
\hline$h m_{m, p}$ & Handling cost of product $\mathrm{p}$ at manufacturer $\mathrm{m}$ \\
\hline$h w_{w, p}$ & Handling cost of product $\mathrm{p}$ at wholesaler $\mathrm{w}$ \\
\hline$T C_{i, j}$ & Transportation cost from node $\mathrm{I}$ to node $\mathrm{j}$ in the network $\mathrm{G}$. \\
\hline$P C M_{m, d, p}$ & Procurement cost of product $\mathrm{p}$ from manufacturer $\mathrm{m}$ to $\mathrm{DC} \mathrm{d}$ \\
\hline$P C S_{s, m, r}$ & Procurement cost of raw material $\mathrm{r}$ from supplier $\mathrm{s}$ to manufacturer $\mathrm{m}$ \\
\hline$P r C_{m, p}$ & Production cost of product $\mathrm{p}$ at manufacturer $\mathrm{m}$ \\
\hline$P C W_{d, w, p}$ & Procurement cost of product $\mathrm{p}$ from $\mathrm{DC}$ d to wholesaler $\mathrm{w}$ \\
\hline$L C_{d, c, p}$ & Delivery Lead time for product $\mathrm{p}$ from $\mathrm{DC} \mathrm{d}$ to customer $\mathrm{c}$ \\
\hline$L D_{m, d, p}$ & Lead time for product $\mathrm{p}$ from manufacturer $\mathrm{m}$ to $\mathrm{DC} \mathrm{d}$ \\
\hline$L D_{s, m, r}$ & Delivery lead time for raw material $\mathrm{r}$ from supplier $\mathrm{s}$ to manufacturer $\mathrm{m}$ \\
\hline$C D_{d, t}$ & Storage capacity of DC $\mathrm{d}$ in period $\mathrm{t}$ \\
\hline$C M_{m, t}$ & Storage capacity of manufacturer $\mathrm{m}$ in period $\mathrm{t}$ for finish product \\
\hline$C P_{m, t}$ & Production capacity of manufacturer $\mathrm{m}$ in period $\mathrm{t}$ \\
\hline$C R_{m, t}$ & Storage capacity of manufacturer $\mathrm{m}$ in period $\mathrm{t}$ for raw material \\
\hline$C S_{s, r, t}$ & Capacity of supplier $\mathrm{s}$ in period $\mathrm{t}$ for raw material $\mathrm{r}$ \\
\hline$S C_{m, p}$ & Setup cost of product $\mathrm{p}$ at manufacturer $\mathrm{m}$ \\
\hline$\mu_{m, p}$ & Utilization rate of capacity in manufacturer $\mathrm{m}$ when producing one unit of product $\mathrm{p}$ \\
\hline$\sigma_{r, p}$ & Rate of raw material $\mathrm{r}$ to producing one unit of product $\mathrm{p}$ \\
\hline$\delta_{m, p}$ & Setup time of product $\mathrm{p}$ at manufacturer $\mathrm{m}$ \\
\hline
\end{tabular}

Table 2: Variables

\begin{tabular}{|l|l|}
\hline$I D_{d, p, t}$ & Stock level of product $\mathrm{p}$ at $\mathrm{DC} \mathrm{d}$ and period $\mathrm{t}$ \\
\hline$I M_{m, p, t}$ & Stock level of product $\mathrm{p}$ at manufacturer $\mathrm{m}$ and period $\mathrm{t}$ \\
\hline$I W_{w, p, t}$ & Stock level of product $\mathrm{p}$ at wholesaler and period $\mathrm{t}$ \\
\hline$I R_{m, r, t}$ & Stock level of raw material $\mathrm{r}$ at manufacturer $\mathrm{m}$ and period $\mathrm{t}$ \\
\hline$Q D_{m, d, p, t}$ & Quantity of product $\mathrm{p}$ procured from manufacturer $\mathrm{m}$ to $\mathrm{DC} \mathrm{d}$ in period $\mathrm{t}$ \\
\hline$Q W_{d, w, p, t}$ & Quantity of product $\mathrm{p}$ procured from $\mathrm{DC} \mathrm{d}$ to wholesaler $\mathrm{w}$ in period $\mathrm{t}$ \\
\hline$Q M_{m, p, t}$ & Quantity of product $\mathrm{p}$ produced at manufacturer $\mathrm{m}$ in period $\mathrm{t}$ \\
\hline$Q R_{s, m, r, t}$ & Quantity of raw material $\mathrm{r}$ procured from supplier $\mathrm{s}$ to manufacturer $\mathrm{m}$ in period $\mathrm{t}$ \\
\hline$D M_{m, p, t}$ & Demands of product $\mathrm{p}$ at manufacturer $\mathrm{m}$ in period $\mathrm{t}$ \\
\hline$D D_{m, p, t}$ & Demands of product $\mathrm{p}$ at $\mathrm{DC} \mathrm{d}$ in period $\mathrm{t}$ \\
\hline$D R_{m, r, t}$ & Demands of raw material $\mathrm{r}$ for manufacturer $\mathrm{m}$ in period $\mathrm{t}$ \\
\hline$\lambda D_{d, w, p, t}$ & $\begin{array}{l}\text { Binary variable set to } 1, \text { if } \mathrm{DC} \text { d is chosen for wholesaler } \mathrm{w} \text { needs of product } \mathrm{p} \text { in period } \mathrm{t} ; 0 \\
\text { otherwise }\end{array}$ \\
\hline$\lambda W_{w, c, p, t}$ & $\begin{array}{l}\text { Binary variable set to } 1, \text { if wholesaler } \mathrm{w} \text { is chosen for customer } \mathrm{c} \text { needs of product } \mathrm{p} \text { in } \\
\text { period } \mathrm{t} ; 0 \text { otherwise }\end{array}$ \\
\hline$\lambda M_{m, d, p, t}$ & $\begin{array}{l}\text { Binary variable set to } 1, \text { if manufacturer } \mathrm{m} \text { is chosen for } \mathrm{DC} \mathrm{d} \text { needs of product } \mathrm{p} \text { in period } \\
\mathrm{t} ; 0 \text { otherwise }\end{array}$ \\
\hline$S E_{m, p, t}$ & Binary variable set to 1, if there is a setup of product $\mathrm{p}$ in $\mathrm{t} ; 0$ otherwise \\
\hline
\end{tabular}




\subsubsection{Customer - Wholesaler Model}

In this stage, the customers make orders to wholesalers. The wholesaler's aims to minimize the costs related to handling stock, procurement from wholesalers and transportation. Let $f_{1}$ be the objective function of this level:

$f_{1}=\sum_{p=1}^{P} \sum_{w=1}^{W} \sum_{t=1}^{T}\left(\left(h w_{d, p} * Q W * I W_{w, p, t}\right)+\sum_{d \in D}\left(P C W_{w, d, p} * Q W_{w, d, p, t}\right)+\sum_{c \in C}\left(\lambda W_{w, c, p, t} * T C_{w, c}\right)\right)$

The minimization of $f_{1}$ is subject to the inventory and capacity constraints.

The customer demands placed in period $t$ should be shifted to the period $t-L C_{p, w, c}$ in the wholesaler's consideration to meet the customer due-date. The wholesaler's demands are equal to the assigned customers' demands.

$$
\begin{aligned}
& D W_{w, p, t} \geq \sum_{c \in C} D C_{c, p,(t+L, c, c, p)} * \lambda W_{w, c, p, t}, \quad \forall w, \forall p, \forall t \\
& I W_{w, p, t}=I W_{w, p,(t-1)}+\sum_{c \in C} D C_{c, p,\left(t+L C_{w, c, p}\right)} * \lambda W_{w, c, p, t,} \quad \forall w, \forall p, \forall t \\
& \sum_{p \in P} I W_{w, p, t} \leq C W_{w, t} \quad \forall w, \forall t
\end{aligned}
$$

The customer demand in a period $t$ should be covered by one wholesaler.

$\sum_{w \in W} \lambda W_{w, c, p, t}=1, \forall p \in P, \forall c \in C, \forall t=1 \ldots T$

Constraints (1.1) compute the demand at wholesaler's level, taking into account the assignment of customer to wholesaler. The balancing stock is respected by imposing the constraints (1.2). The inventory is limited by the available capacity (constraints (1.3).

The following constraints define the nature of each variable.

$$
\begin{aligned}
& Q W_{d, w, p, t} \in N, \quad \forall d, p, w, t . \\
& \lambda W_{W, c, p, t} \in\{0,1\}, \quad \forall d, p, c, t . \\
& I W_{w, p, t} \in N, \quad \forall p, w, t .
\end{aligned}
$$

\subsubsection{Wholesalers - DCs Model}

In this stage, the wholesalers make orders to DCs. The DCs aims to minimize the costs related to handling stock, procurement from DCs and transportation. Let $f_{2}$ be the objective function of this level:

$f_{2}=\sum_{p=1}^{P} \sum_{d=1}^{D} \sum_{t=1}^{T}\left(\left(h d_{d, p} * I D_{d, p, t}\right)+\sum_{m \in M}\left(P C D_{m, d, p} * Q D_{m, d, p, t}\right)+\sum_{w \in W}\left(\lambda D_{d, W, p, t} * T C_{d, W}\right)\right)$

The minimization of $f_{3}$ is subject to the inventory and capacity constraints.

The wholesalers demand placed in period $t$ should be shifted to the period $t-L C_{p, d, c}$ in the DC consideration to meet the wholesalers' due-date. The DC demands are equal to the assigned wholesaler's demands.

$$
\begin{aligned}
& D D_{d, p, t} \geq \sum_{c \in C} D W_{W, p,\left(t+L C_{d, w, p}\right)} * \lambda D_{d, w, p, t}, \quad \forall d, \forall p, \forall t \\
& I D_{d, p, t}=I D_{d, p,(t-1)}+\sum_{m \in M} Q D_{m, d, p, t}-D D_{d, p, t,} \quad \forall d, \forall p, \forall t \\
& \sum_{p \in P} I D_{d, p, t} \leq C D_{d, t} \quad \forall d, \forall t
\end{aligned}
$$

The wholesaler's demand in a period t should be covered by one DC. 
$\sum_{d \in D} \lambda D_{d, c, p, t}=1, \forall p \in P, \forall c \in C, \forall t=1 \ldots T$

Constraints (2.1) compute the demand at DCs level, taking into account the assignment of wholesaler to DC. The balancing stock is respected by imposing the constraints (2.2). The inventory is limited by the available capacity (constraints (2.3). The following constraints define the nature of each variable.

$$
\begin{aligned}
& Q D_{m, p, d, t} \in N, \quad \forall m, p, d, t . \\
& \lambda D_{d, c, p, t} \in\{0,1\}, \quad \forall d, p, c, t . \\
& I D_{d, p, t} \in N, \quad \forall p, d, t .
\end{aligned}
$$

\subsubsection{DCs - Manufacturer Model}

The objective at the manufacturing level is to minimize production handling costs, production costs, and transportation costs in responding to all order of lower level. Let $f_{3}$ be the objective function at this level.

$f_{3}=\sum_{p=1}^{P} \sum_{m=1}^{M} \sum_{t=1}^{T}\left(\left(h m_{m, p} * I M_{m, p, t}\right)+\left(P r C_{m, p} * Q M_{m, p, t}\right)+\left(S C_{m, p} * S E_{m, p, t}\right)+\sum_{d \in D}\left(\lambda M_{m, d, p, t} * T C_{m, d}\right)\right)$

The constraints of capacity and stock handling should be respected. Note that in this level two type of capacity are considered: storage capacity and production capacity.

$D M_{m, p, t} \geq \sum_{d \in D} D D_{d, p,\left(t+L D_{m, d, p}\right)} * \lambda M_{m, d, p, t}, \quad \forall m, \forall p, \forall t$

$I M_{m, p, t}=I M_{m, p,(t-1)}+Q M_{m, p, t}-D M_{m, p, t,} \quad \forall m, \forall p, \forall t$

$\sum_{p \in P} I M_{m, p, t} \leq C M_{m, t} \quad \forall m, \forall t$

$\sum_{p \in P}\left(\mu_{m, p} * Q M_{m, p, t}+\delta_{m, p} * S E_{m, p, t}\right) \leq C P_{m, t} \quad \forall m, \forall t$

$Q M_{m, p, t} \leq B M * S M_{m, p, t} \quad \forall m, \forall p, \forall t$

The DC demand in a period t should be covered by one manufacturer.

$\sum_{m \in M} \lambda M_{m, d, p, t}=1, \forall p \in P, \forall d \in D, \forall t=1 \ldots T$

The DCs demands are computed according to the customer selection to each DC (the constraints (3.1). The stock in a period should be balanced by the demand and the production at the same period and the stock of the previous period (the constraints (3.2). The production capacities consider the processing time and the setup time (the constraints (3.4). The constraints (3.5) impose that if there is no setup, no production is launched. Otherwise, the production is limited by a big number BM. The following constraints define the nature of each variable.

$$
\begin{aligned}
& Q D_{m, p, t} \in N, \quad \forall m, p, t . \\
& \lambda M_{m, d, p, t} \in\{0,1\}, \quad \forall m, d, p, t . \\
& I M_{m, p, t} \in N, \quad \forall m, p, t .
\end{aligned}
$$

\subsubsection{Supplier - Manufacturer Model}

The Supplier-Manufacturer level involves procurement, the objective is to supply manufacturers with the raw materials necessary for production. The composition of products is provided by the bill of materials $(\mathrm{BOM})$. Based on the BOM, the raw material requirement is determined. The objective, for which the function denoted $f 4$, is to minimize procurement and handling costs. 
$f_{4}=\sum_{r=1}^{R} \sum_{m=1}^{M} \sum_{t=1}^{T}\left(\left(h m_{m, r} * I R_{m, r, t}\right)+\sum_{s=1}^{S}\left(P C S_{s, m, r} * Q R_{s, m, r, t}\right)\right)$

As for the previous models, this model is subjected to the capacity and handling stock constraints. The raw material demand is at least equal to the demand of product at manufacturer that may not be honored by inventory or production.

$D R_{m, r, t} \geq \sum_{p \in P} Q D_{m, p,\left(t-L D_{s, m, r}\right)} * \sigma_{r, p,} \quad \forall m, \forall r, \forall t$

$I R_{m, r, t}=I R_{m, r,(t-1)}+\sum_{s=1}^{S} Q R_{s, m, r, t}-D R_{m, r, t,} \quad \forall m, \forall r, \forall t$

$\sum_{r \in R}\left(I R_{m, r, t} \leq C M R_{m, t} \quad \forall m, \forall t\right.$

For a supplier, the total order for a material raw should not exceed its capacity.

$\sum_{m \in M} Q R_{s, m, r, t} \leq C S_{s, r, t}, \forall s, \forall r, \forall t$

Constraint (4.1) imposes that the raw material demand should be at least equal to product demand multiply by the rate $\sigma$. While, constraints (4.3) emphasizes that the inventory of each period is limited by the manufacturer capacity.

The nature of each variable is defined by the following constraints.

$$
Q R_{s, m, p, t} \in N, \quad \forall s, m, p, t .
$$

$$
I R_{m, r, t} \in N, \quad \forall m, r, t
$$

\subsection{Solution Methodology}

To solve the global optimization problem of a manufacturing company SC, the global model including the four objective functions $\left(f_{1}, f_{2}, f_{3}\right.$ and $\left.f_{4}\right)$ and the constraints of the four sub-models must be optimized. However, this global model is very large in number of variables and constraints. The strategy is to solve the different problems separately and coordinate between the levels by exchanging outputs and inputs. This procedure starts by considering customer orders to compute the wholesaler's requirements. This is done using the Costumer-Wholesalers model. The output of this model allows the computation of demands at the wholesalers-DCs level. The output of this model allows the computation of demands at the manufacturer level. Knowing the manufacturers requirement, it is then possible to compute production quantities and the raw materials requirement for each one of them. In this stage, the Manufacturer model is used. Finally, at the last level, the supplier model is used to compute the raw material that should be procured from the suppliers to each manufacturer.

\section{EXPERIMENTATION}

To illustrate the newly proposed solution, an example is developed in this section to validate our methodology using the case study earlier mentioned. The comparison of our methodology to the current system is complicated due to the confidentiality of the company data. It is difficult to find in literature benchmarks that correspond to our SC scheme. For this purpose, we compare the obtained solutions with a heuristic developed regarding the current functioning process of the company SC. According to our knowledge, this heuristic describes with a good level of adequacy the behavior of WEMY SC managers. This heuristic is given below: 


\subsection{Illustrative example}

At this stage, we do not have complete data sets. Thus, to fix the input data used, the same strategies presented by (Sabri and Beamon, 2000), (Wolosewicz et al. 2006) and (El Yasmine et al. 2012) to generate randomly instances have been used.

The following parameters are considered:

- $\quad$ Number of customers (zone) $=2$

- Number of DCs = 2

- Number of wholesalers $=2$

- Number of plants $=2$

- Number of suppliers $=6$

- Number of raw materials $=17$

- $\quad$ Number of period $=4$

Delivery time between different levels is set to one period. The initial inventory is set 0 at all levels. The customer demand is given by the following matrix (for each product $p$, and each period $t$ ), see tables below:

Table 3: Customers demands Customer 1

\begin{tabular}{|l|l|l|l|l|}
\hline & $\mathrm{t} 1$ & $\mathrm{t} 2$ & $\mathrm{t} 3$ & $\mathrm{t} 4$ \\
\hline $\mathrm{p} 1$ & 8 & 6 & 1 & 4 \\
\hline $\mathrm{p} 2$ & 4 & 7 & 0 & 4 \\
\hline
\end{tabular}

Customer 2
\begin{tabular}{|l|l|l|l|l|}
\hline & $\mathrm{t} 1$ & $\mathrm{t} 2$ & $\mathrm{t} 3$ & $\mathrm{t} 4$ \\
\hline p1 & 2 & 9 & 3 & 3 \\
\hline p2 & 9 & 3 & 4 & 7 \\
\hline
\end{tabular}

The different parameters and input data are uniformly generated in the intervals as shown below.

Table 4: Parameters and Input data

\begin{tabular}{|l|l|}
\hline Parameter & Interval \\
\hline The inventory costs at all levels & {$[3,6]$} \\
\hline The procurement costs from DC to wholesalers & {$[5,16]$} \\
\hline The procurement costs from manufacturer to DC & {$[7,18]$} \\
\hline $\begin{array}{l}\text { The procurement costs from supplier to } \\
\text { manufacturer }\end{array}$ & {$[100,250]$} \\
\hline $\begin{array}{l}\text { The transportation costs from wholesaler to } \\
\text { customer }\end{array}$ & {$[10,30]$} \\
\hline The transportation costs from DCs to wholesaler & {$[20,40]$} \\
\hline The transportation costs from plants to DCs & {$[30,50]$,} \\
\hline $\begin{array}{l}\text { The storage capacities of DCs, manufacturers and } \\
\text { suppliers }\end{array}$ & $\begin{array}{l}\text { Generated according to demands at each } \\
\text { level. }\end{array}$ \\
\hline The production cost at plants & {$[5,16]$} \\
\hline The setup time & {$[1,30]$} \\
\hline The setup cost & According to setup time \\
\hline The consumption rate of product & Rate $[10 \%, 60 \%]$ of capacity \\
\hline Rate of raw material in product & {$[0,20]$} \\
\hline
\end{tabular}

The proposed solution methodology gave the following results as tabulated below: 
Table 5: Calculated demands of Wholesalers

For w1

\begin{tabular}{|l|l|l|l|l|}
\hline & $\mathrm{t} 1$ & $\mathrm{t} 2$ & $\mathrm{t} 3$ & $\mathrm{t} 4$ \\
\hline $\mathrm{p} 1$ & 0 & 4 & 0 & 0 \\
\hline $\mathrm{p} 2$ & 0 & 4 & 0 & 0 \\
\hline
\end{tabular}

For $\mathrm{w} 2$
\begin{tabular}{|l|l|l|l|l|}
\hline & $\mathrm{t} 1$ & $\mathrm{t} 2$ & $\mathrm{t} 3$ & $\mathrm{t} 4$ \\
\hline $\mathrm{p} 1$ & 15 & 0 & 7 & 0 \\
\hline $\mathrm{p} 2$ & 10 & 0 & 11 & 0 \\
\hline
\end{tabular}

Table 6: Calculated demands of DCs

Demands of d1

\begin{tabular}{|l|l|l|l|l|}
\hline & $\mathrm{t} 1$ & $\mathrm{t} 2$ & $\mathrm{t} 3$ & $\mathrm{t} 4$ \\
\hline $\mathrm{p} 1$ & 4 & 0 & 0 & 0 \\
\hline $\mathrm{p} 2$ & 4 & 0 & 0 & 0 \\
\hline
\end{tabular}

Demands ofd2

\begin{tabular}{|l|l|l|l|l|}
\hline & $\mathrm{t} 1$ & $\mathrm{t} 2$ & $\mathrm{t} 3$ & $\mathrm{t} 4$ \\
\hline $\mathrm{p} 1$ & 0 & 7 & 0 & 0 \\
\hline $\mathrm{p} 2$ & 0 & 11 & 0 & 0 \\
\hline
\end{tabular}

Demands of $\mathrm{m} 2$

Demands of $\mathrm{m} 1$

\begin{tabular}{|l|l|l|l|l|}
\hline & $\mathrm{t} 1$ & $\mathrm{t} 2$ & $\mathrm{t} 3$ & $\mathrm{t} 4$ \\
\hline $\mathrm{p} 1$ & 0 & 0 & 0 & 0 \\
\hline $\mathrm{p} 2$ & 0 & 0 & 0 & 0 \\
\hline
\end{tabular}

\begin{tabular}{|l|l|l|l|l|}
\hline & $\mathrm{t} 1$ & $\mathrm{t} 2$ & $\mathrm{t} 3$ & $\mathrm{t} 4$ \\
\hline $\mathrm{p} 1$ & 7 & 0 & 0 & 0 \\
\hline $\mathrm{p} 2$ & 11 & 0 & 0 & 0 \\
\hline
\end{tabular}

As we can see in those tables, the customer demands are aggregated at wholesaler's level. All customer demands of the first period are ignored since the delivery time is one period. The demand of product $\mathrm{p} 1$ is affected to wholesaler w2. The wholesaler's demand in the first period equals to 15 including the two customer's demand at period 2 (6 and 9).

\subsubsection{Customer - Wholesaler model:}

$f_{1}=\sum_{p=1}^{P} \sum_{w=1}^{W} \sum_{t=1}^{T}\left(\left(h w_{d, p} * Q W * I W_{w, p, t}\right)+\sum_{d \in D}\left(P C W_{w, d, p} * Q W_{w, d, p, t}\right)+\sum_{c \in C}\left(\lambda W_{w, c, p, t} * T C_{w, c}\right)\right)$

$=\{[(6 \times 0)+(5 \times 0+5 \times 1)+(10 \times 1+10 \times 1)]$

$[(6 \times 15)+(5 \times 4+5 \times 0)+(10 \times 1+10 \times 1)]$

$[(6 \times 4)+(5 \times 0+5 \times 7)+(10 \times 1+10 \times 1)]$

$[(6 \times 7)+(5 \times 0+5 \times 0)+(10 \times 1+10 \times 1)]$

$[(6 \times 10)+(5 \times 4+5 \times 0)+(10 \times 1+10 \times 1)]$

$[(6 \times 4)+(5 \times 0+5 \times 11)+(10 \times 1+10 \times 1)]$

$[(6 \times 11)+(5 \times 0+5 \times 0)+(10 \times 1)]\}$

$=\{(25)+(130)+(79)+(62)+(100)+(99)+(76)\}=571$

The total cost at this level, calculated using the function $f_{1}$, according to the generated data is equal to 571.

\subsubsection{Wholesaler - DCs model:}

$f_{2}=\sum_{p=1}^{P} \sum_{d=1}^{D} \sum_{t=1}^{T}\left(\left(h d_{d, p} * I D_{d, p, t}\right)+\sum_{m \in M}\left(P C D_{m, d, p} * Q D_{m, d, p, t}\right)+\sum_{w \in W}\left(\lambda D_{d, W, p, t} * T C_{d, W}\right)\right)$

$=\{[(6 \times 0)+(18 \times 0+18 \times 1)+(20 \times 1)]$

$[(6 \times 4)+(18 \times 0+18 \times 7)+(20 \times 1)]$

$[(6 \times 7)+(18 \times 0+18 \times 0)+(20 \times 1)]$

$[(6 \times 4)+(18 \times 0+18 \times 11)+(20 \times 1)]$

$[(6 \times 11)+(18 \times 0+18 \times 0)+(20 \times 1)]\}$

$=\{(38)+(170)+(62)+(242)+(86)\}=598$

In the DCs level the demand are given in table 6 (for Dc d1 and d2). The decision taken by the model at this stage is to direct the highest quantity of demand of product to d2.

The total cost is equal to 598 including production cost and transportation cost (calculated using the function $f_{2}$ ). 


\subsubsection{DCs - Manufacturer model:}

$$
\begin{aligned}
& f_{3}=\sum_{p=1}^{P} \sum_{m=1}^{M} \sum_{t=1}^{T}\left(\left(h m_{m, p} * I M_{m, p, t}\right)+\left(P r C_{m, p} * Q M_{m, p, t}\right)+\left(S C_{m, p} * S E_{m, p, t}\right)+\sum_{d \in D}\left(\lambda M_{m, d, p, t} * T C_{m, d}\right)\right) \\
& =\{[(6 \times 0)+(18 \times 0+18 \times 1)+(30 \times 1)+(20 \times 1)] \\
& {[(6 \times 7)+(18 \times 0+18 \times 7)+(30 \times 1)+(20 \times 1)]} \\
& [(6 \times 11)+(18 \times 0+18 \times 11)+(30 \times 1)+(20 \times 1)]\} \\
& =\{(68)+(218)+(314)\}=600
\end{aligned}
$$

In the manufacturer level the demand are given in table 7 (for manufacturer $\mathrm{m} 1$ and $\mathrm{m} 2$ ). The decision taken by the model at this stage is to direct the highest quantity of demand of product to $\mathrm{m} 2$.

The total cost is equal to 600 including production cost, setup cost and transportation cost (calculated using the function $f_{3}$ ).

Finally, to produce the manufacturer demands, the plant $\mathrm{m} 2$ receives the raw material from supplier (9 and 8 for each raw material).

\subsubsection{Supplier - Manufacturer model:}

$$
\begin{aligned}
f_{4}= & \sum_{r=1}^{R} \sum_{m=1}^{M} \sum_{t=1}^{T}\left(\left(h m_{m, r} * I R_{m, r, t}\right)+\sum_{s=1}^{S}\left(P C S_{s, m, r} * Q R_{s, m, r, t}\right)\right) \\
& \quad 9 \times 6=54 ; 8 \times 6=48 \\
= & \{(4 \times 17)+(150 \times 54+150 \times 48)\} \\
= & \{(68)+(8100)+(7200)\} \\
= & 15368
\end{aligned}
$$

The total cost at supplier level, calculated using the function $f_{4}$, is equal to 15368 .

Total $=(571+598+600+15368)=17137$

For comparison purpose, the execution of the planning heuristics has been made. Another solution more expensive than the one obtained by the model has been found. This solution is equal to 19712 (740 at the first level, 638 at the second level, and 586 at the third level and 17748 at the last level).

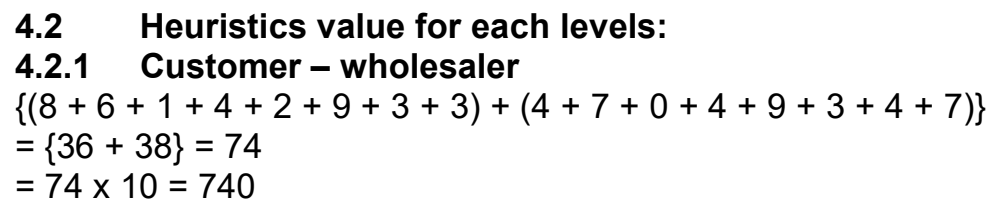

(Where 10 is the summation of the numbers of product, wholesalers, manufacturers, customers and the time T).

\subsubsection{Wholesaler - DCs}

$\{(4+15+7)+(4+10+11)\}$

$=\{26+25\}=51$

$=51 \times 2=102$

(Where 2 is representing the number of customers that got the products from the wholesaler).

$=740-102=638$

\subsubsection{DCs - manufacturer}

$\{(4+7)+(4+11)\}$

$=\{11+15\}=26$

$=26 \times 2=52$

(Where 2 is representing the number of wholesalers that got the products from the distribution centers). $=638-52=586$ 


\subsubsection{Supplier}

$\{(54)+(48)\}=102$

$\{74+51+26+23\}=174$

$=174 \times 102=17748$

The table below shows the cost obtained by using the heuristic $(\mathrm{H})$ and the mathematical model (MM), according to the values given.

Table 8: Cost obtained by $\mathrm{H}$ and MM

\begin{tabular}{|c|c|c|c|}
\hline $\begin{array}{c}\text { Configuration } \\
\text { C,P,W,D,M,S,R,T }\end{array}$ & $\begin{array}{c}\text { Heuristics result } \\
(\mathrm{HR})\end{array}$ & $\begin{array}{c}\text { Mathematical model } \\
\text { result(MMR) }\end{array}$ & GAP \% \\
\hline $2,2,2,2,2,6,17,4$ & 19712 & 17137 & 15.02 \\
\hline
\end{tabular}

To analyze the performance of the mathematical model, we use the GAP given by the following formulas:

$$
G A P=\frac{H R-M M}{M M R} \times 100
$$

The proposed model improves the actual solution by $15.02 \%$.

\section{CONCLUSION}

In this paper, we reviewed and extended the mathematical model originally proposed (by El Yasmine et al. 2012) to include wholesalers, to optimize SC taking into consideration some innovative constraints. In every company, the main objective is to maximize profit and also reduce cost of production. As well as, to ensure satisfaction of costumers' demand in terms of costs and real delivery dates. The proposed solution methodology was compared to a heuristics modeling behavior of the industrial managers of WEMY Industries Limited SC. The results obtained by executing the heuristics approach and the mathematical model show that it is more efficient than the heuristic. The GAP $15.02 \%$ gotten from above shows that the proposed model improves the actual solution, it will assist in reducing costs of production and transportation of the goods and profit will be maximize as the customer demands are meant genuinely respecting the delivery date of the customer. The proposed model has been extended to include wholesalers. Consideration of details in the raw materials acquisition and different production types for each manufacturer can be a good future contribution because of product diversity, product categories, weight and use. Also, expiration dates should be integrated. 


\section{REFERENCES}

1. Al-Ameri, T. A., N. Shah, and L.G. Papageorgiou, (2008). Optimization of vendor managed inventory systems in a rolling horizon framework. Computers \& Industrial Engineering, 54, p. 10191047.

2. Aliev, R.A., B. Fazlollahi, B.G. Guirimov, R.R. Aliev, (2007). Fuzzy-genetic approach to aggregate production-distribution planning in supply chain management. Information Sciences. 177, 42414255.

3. Axsäter, S. (2015). Inventory Control. Third edition. International Series in Operations Research \& Management Science volume 225. Cham, Heidelberg, NewYork, Dordrecht, London: Springer International Publishing

4. Bilgen, B., (2010). Application of fuzzy mathematical programming approach to the production allocation and distribution supply chain network problem. Expert Systems with Applications, 37, p. 4488-4495.

5. Chen, C.L., B.W. Wang, W.C. Lee, (2003). Multiobjective optimization for a multienterprise supply chain network. Industrial and Engineering Chemistry Research, 42, p.1879-1889.

6. Dondo, R., C.A. Mendez, and J. Cerda, (2008). Solving multiple vehicle pickup and delivery problems in multisite systems by a rigorous optimization approach. In L.G. Papageorgiou, \& M. C. Georgiadis (Eds.), Supply chain optimization: Part I. p. 29-60.Weinheim: Wiley-VCH.

7. El Yasmine Ait Si Larbi, Abdelghani Bekrar, Damien Trentesaux, Bouziane Beldjilali, (June 2012). Multi-Stage Optimization In Supply Chain: An Industrial Case Study. 9th International Conference on Modeling, Optimization, Simulation, Bordeaux, France.

8. Funaki, K., (2010). Strategic safety stock placement in supply chain design with due-date based demand. Int. J. Production Economics, 135, p. 4-13.

9. Huang, C., and I.A. Karimi, (2006). Scheduling transshipment operations in maritime chemical transportation. Industrial \& Engineering Chemistry Research, 45, 1955-1973.

10. Jindal, Anil, and Kuldip Singh Sangwan. (2014I). "Closed Loop Supply Chain Network Design and Optimisation Using Fuzzy Mixed Integer Linear Programming Model." International Journal of Production Research 52 (14): 4156-73. doi:10.1080/00207543.2013.861948.

11. Jin-Kwang, B., I. E. Grossmann, and S. Park, (2000). Supply chain optimization in continuous flexible process networks. Industrial \& Engineering Chemistry Research, 39, 1279-1290.

12. Kallrath, J., (2002). Combined strategic and operational planning - An MILP success story in chemical industry. OR Spectrum, 24, p.315-341.

13. Karimi, I. A., M. Sharafali, and H. Mahalingam, (2005). Scheduling tank container movements for chemical logistics. AIChE Journal, 51, p.178-197.

14. Lazaros, G. and L.G. Papageorgiou, (2009). Supply chain optimisation for the process industries: Advances and opportunities, Computers and Chemical Engineering, 33, p.1931-1938.

15. Lee, Y.H., S.H. Kim, (2000). Optimal production- distribution planning in supply chain management using a hybrid simulation-analytic approach. Proceedings of the 2000 Winter Simulation Conference 1 and 2, p. 1252-1259.

16. Lim, S.J., S.J. Jeong, K.S. Kim, M.W. Park, (2006). A simulation approach for productiondistribution planning with consideration given to replenishment policies. International Journal of Advanced Manufacturing Technology, 27, 593-603.

17. McDonald, C. M. and I.A Karimi, (1997). Planning and scheduling of parallel semi continuous processes in Production planning. Industrial \& Engineering Chemistry Research, 36, p.2691-2700.

18. Mula, J., D. Peidro, M. Diaz-Madronero, E. Vicens, (2010). Mathematical programming models for supply chain production and transport planning. European Journal of Operational Research, 204, p.377-390.

19. Peidro, D., J. Mula, R. Poler, F.C. Lario., (2008). Quantitative models for supply chain planning under uncertainty: a review. The international Journal of Advanced manufacturing Technology, 43, p. 400-420. ISSN: 02683768. 
20. Peirleitner A.J., Altendorfer K. and Felberbauer T., (2016). A Simulation Approach for Multi-Stage Supply Chain Optimization to Analyze Real World TransportationEffects. Proceedings of the 2016 Winter Simulation Conference, edited by T.M.K. Roeder, P.I. Frazier, R. Szechtman, E. Zhou, T. Huschka, and S.E. Chick. p. 2273-2283.

21. Petridis Konstantinos. (2013). "Optimal Design of Multi-Echelon Supply Chain Networks under Normally Distributed Demand." Annals of Operations Research, July, 1-29. doi:10.1007/s10479013-1420-6

22. Pourya Pourhejezy and Oh Kyoung Kwon, (2016). The New Generation of Operations Research Methods in Supply Chain Optimization: A Review. Sustainability 2016, 8,1033; www.mdpi.com/journal/sustainability, doi:10.3390/su8101033.

23. Roghanian, E., S.J. Sadjadi, M.B. Aryanezhad, (2007). A probabilistic bi-level linear multi-objective programming problem to supply chain planning. Applied Mathematics and Computation, 188, p.786-800.

24. Ryu, J.H., V. Dua, E.N. Pistikopoulos, (2004). A bilevel programming framework for enterprise-wide process networks under uncertainty. Computers and Chemical Engineering, 28, p.1121-1129.

25. Sabri, E.H. and B.M Beamon, (2000). A multi-objective approach to simultaneous strategic and operational planning in supply chain design. Omega: International Journal of Management Science, 28, p. 581-598.

26. Selim, H., C. Am, I. Ozkarahan, (2008). Collaborative production-distribution planning in supply chain: A fuzzy goal programming approach. Transportation Research Part E-Logistics and Transportation Review, 44, 396-419.

27. Simchi-Levi, D., Kaminsky, P., \& Simchi-Levi, E., (1999). Designing and managing the supply chain: Concepts, strategies, and cases. McGraw-Hill.

28. Voudouris, V. T.,( 1996). Mathematical programming techniques to debottleneck the supply chain of fine chemical industries. Computers \& Chemical Engineering, 20, p.1269-1274.

29. Wolosewicz, C, Dauzere-Peres S., Aggoune A., (2006), A new approach for solving integrated planning and scheduling problem, INCOM'O6 (12th IFAC Symposium on Information Control Problems in Manufacturing), vol. 3, pp. 191-196, Saint Etienne, France.

30. Zhalechian, M.; Tavakkoli-moghaddam, R.; Zahiri, B.; Mohammadi, M. (2016). Sustainable design of a closed-loop location-routing-inventory supply chain network under mixed uncertainty. Transp. Res. Part E, 89,182-214. http://dx.doi.org/10.1016/j.tre.2016.02.011 